\title{
Validity of Chinese Version of Attitudes Toward Interprofessional Health Care Teams Scale
}

\author{
Dan $\mathrm{Li}^{1} *$ \\ Ai-li Wang ${ }^{2 * *}$ \\ Yan-fen Gu' \\ Qin Liu $^{3}$ \\ Xiao-min Chen ${ }^{4}$ \\ Zi-ying Wang ${ }^{5}$ \\ Hui-ren Zhuang' \\ Miao $\mathrm{Du}^{6}$ \\ Chi Chen ${ }^{7}$ \\ Hai-ping Yu'
}

'Department of Nursing, Shanghai East Hospital, Tongji University School of Medicine,

Shanghai, People's Republic of China;

${ }^{2}$ Department of Pediatric Clinics, Shanghai

United Family Hospital, Tongii University

School of Medicine, Shanghai, People's

Republic of China; ${ }^{3}$ Department of

Nursing, Shanghai SIPO Polytechnic, Shanghai,

People's Republic of China; ${ }^{4}$ Department of

Finance, Shanghai University of Finance and

Economics, Shanghai, People's Republic of

China; ${ }^{5}$ Department of Nursing, Shanghai

Proton and Heavy lon Center, Shanghai,

People's Republic of China; ${ }^{6}$ Department of

Basic Nursing, School of Nursing and Health

Management, Shanghai University of Medicine

\& Health Sciences, Shanghai, People's Republic

of China; ${ }^{7}$ Department of Teaching and

Training, Shanghai East Hospital, Tongji

University School of Medicine, Shanghai,

People's Republic of China

*These authors contributed equally to this work

Correspondence: Hai-ping Yu

Department of Nursing, Shanghai East

Hospital, Tongji University School of

Medicine, No. 150 Jimo Road, Pudong New

District, Shanghai, People's Republic of China

Tel +86 I350I868I64

Email pingping670@sina.com

Chi Chen

Department of Teaching and Training,

Shanghai East Hospital, Tongji University

School of Medicine, No. 150 Jimo Road,

Pudong New District, Shanghai, People's

Republic of China

$\mathrm{Tel}+86$ I8930935I7|

Email chichen2003@163.com
Objective: Effective teamwork can provide safe and effective care in various medical systems. Thus, there is increasing recognition of the value of interprofessional collaborative practice. The Attitudes Toward Interprofessional Health Care Teams Scale (ATIHCTS) has been applied to a wide variety of health professions for evaluating attitudes toward health care teams. The ATIHCTS has been widely used internationally, but no Chinese version has been developed. The aim of this study was to adapt a Chinese version of the ATIHCTS among Chinese health care professionals and to test its validity.

Methods: The English version of the ATIHCTS was translated into Chinese, backtranslated, and modified for cultural adaptation according to Brislin's guideline. A total of 306 health professionals in a Shanghai tertiary hospital were investigated using the Chinese version of the ATIHCTS to test its validity.

Results: The Chinese version of the ATIHCTS was adjusted based on expert review and pilot testing. According to expert opinions, the text that did not conform to the Chinese language habits and the Chinese medical environment was adjusted. A total of five adjustments were made. After the pilot testing, minor corrections were made to improve the sentence structure of the scale instructions to make it easier to understand. Factor analysis was subsequently conducted with 306 respondents. The Chinese version of the ATIHCTS had 14 items. Exploratory factor analysis extracted two common factors, quality of care and time constraints, with the cumulative variance contribution rate reaching $70.011 \%$ and the load value of each entry on its common factor $>0.4$. In addition, for scale confirmatory factor analysis (CFA), the chi-square/degrees of freedom ratio $\left(\mathrm{X}^{2} / \mathrm{df}\right)$ was 1.46 , the normed fit index (NFI) was 0.97 , the Tucker-Lewis index (TLI) was 0.99 , the incremental fit index (IFI) was 0.99 , the comparative fit index (CFI) was 0.99 , and the root mean square error of approximation (RMSEA) was 0.04 . The fitting values all met the judgment criteria, and the scale had good structural validity. Cronbach's $\alpha$ of the Chinese version of the ATIHCTS was 0.861 , and the Cronbach's $\alpha$ values of each factor were 0.949 and 0.838 , respectively. The split-half reliability was 0.644 , and the Guttman splithalf coefficients of each factor were 0.904 and 0.779 , respectively.

Conclusion: The Chinese version of the ATIHCTS has good validity. It is a valuable tool for evaluating attitudes toward interprofessional health care teams among the health care professionals in China.

Keywords: interprofessional health care teams, attitudes, reliability, validity

\section{Introduction}

The health care field has challenging tasks and many different professions. The delivery of effective and safe health care to patients is highly dependent on patientcentered collaboration between health care professionals. ${ }^{1}$ Interdisciplinary health care requires individual team members, such as physicians, nursing staff, and allied 
health professionals, to collaborate and engage in teamwork. ${ }^{2}$ Effective teamwork reduces medical errors, mortality, hospital expenses, and nurse turnover and increases patient satisfaction and job satisfaction. ${ }^{1,3}$ When health care professionals work together as a team, patient-centered care is at its best, with each member providing guidance on their area of expertise, ${ }^{4}$ and effective teamwork can provide safe and effective care in various medical systems. ${ }^{2}$ Lack of collaboration awareness leads to a reduction of inter-professional teamwork and failure to achieve the desired state.

There is increasing recognition of the value of interprofessional collaborative practice. Experts agree that effective teamwork anchors safe and effective care at various levels of health care systems, leading to a shift toward team research and training. ${ }^{2}$ The World Health Organization (WHO) states that interprofessional education (IPE) plays an important role in addressing the challenges and reducing the problems in the health care system by promoting effective collaboration. ${ }^{5}$ The WHO recognizes that IPE "occurs when two or more professions learn with, about, and from each other to enable effective collaboration and improve health outcomes." larly important in the context of populations with increasing prevalence of long-term conditions and multimorbidity. Training health care providers in interprofessional collaborative practice is an important step to improve patient care and experiences, enhance population health, and reduce costs. The evaluation of the ATIHCTS can effectively assist the trainer to understand the basic situation of the team and use it to evaluate the effectiveness of the training program designed to teach the skills of teamwork and foster positive attitudes about health care teams. To optimize future planning of curricula for continuing IPE, it is essential to evaluate interprofessional attitudes when health care professional graduates enter the workforce. ${ }^{7}$ To evaluate health professionals' attitudes toward interprofessional health care teams, Curran et al developed a detailed scale in $2008,{ }^{8}$ which consisted of 14 Likert-type items that were adopted from the study of Heinemann et al. ${ }^{9}$ The original Attitudes Toward Health Care Teams Scale (ATHCTS) was developed by Professors Heinemann and Schmitt in 1999 to measure general attitudes of health care team members. ${ }^{10}$ The ATHCTS can be used as a pre- and posttest measure or longitudinal monitor of attitudes toward health care teams among team members and/or trainees and their supervisors in clinically based team training programs. ${ }^{11}$ Curran et al adapted the ATHCTS to ATIHCTS, which consisted of 14 items with two subscales: Quality of Care with 11 items and Time Constraints with three items. ${ }^{8}$ The scale, which has been applied for a wide variety of health professions, has been used in Indonesia, Canada, Japan, New Zealand, the United States, and Singapore to measure attitudes toward interprofessional health care teams. ${ }^{5,8,12-15}$

Most Chinese health profession education programs are based on independent professional teaching, which leads to a lack of interprofessional collaboration among different professions and interdisciplinary cooperation opportunities. The lack of interprofessional teamwork was found to be an important reason leading to medical errors in China. ${ }^{16}$ The ATIHCTS has been widely used in many countries. However, its application in China is still in its initial stage, and no Chinese version has been developed. To facilitate the use of the instrument by other researchers for evaluating interprofessional collaborative practice in China, the purpose of this study was to adapt a Chinese version of the ATIHCTS among Chinese health care professionals and to test its validity.

\section{Methods ATIHCTS}

The ATIHCTS was used for data collection, since it has been applied to a wide variety of health professions for evaluating attitudes toward health care teams. In our survey, the 14-item instrument has a 5-point Likert scale ranging from 1 (strongly disagree) to 5 (strongly agree). This scale has two subscales: three items (2, 6, and 9) load onto the Time Constraints subscale, and the remaining 11 items load onto the Quality of Care subscale. The three items regarding time constraints are reverse coded because they are negative statements. The total score range of the scale is $26-58$ points. Higher total scores indicate more positive attitudes toward interprofessional health care teams.

\section{Translation Procedures}

After obtaining authorization from the author of the scale via email, the English version of the ATIHCTS was translated into Chinese, back-translated, and modified for cultural adaptation according to Brislin's guideline. The scale was independently translated into Chinese by two professional bilingual translators with Chinese as their native language. The researcher compared and merged the two translations word by word and formed the first translated 
version. Two bilingual professionals with master's degrees and learning experience abroad back-translated the Chinese version of the ATIHCTS into English separately. Then, a combined back-translated manuscript was formed. A professional bilingual medical expert compared both back-translated English versions with the original version of the ATIHCTS to ensure no differences in translation and produced the final version of the Chinese ATIHCTS. An expert committee comprising eight experts, each with more than 10 years' work experience, was invited to evaluate and revise the Chinese version of the ATIHCTS. According to their expert opinions, the text that did not conform to the Chinese language habits and the Chinese medical environment was adjusted. A total of five adjustments were made: "Interprofessional" in the title, "whole persons" in item 1, "the give and take among team members" in item 3, "unnecessarily complicates things" in item 6 , and "responsive" in item 10. Finally, the Chinese version of the ATIHCTS was established.

The translated version was pilot tested among 37 health care professionals working in clinical practice (31 nurses and six physicians) at one hospital in Shanghai. During the testing, participants were asked to complete the Chinese version of the ATIHCTS. For each item, the participants had the opportunity to comment on the language, understandability, and clarity. Minor corrections were made to improve the sentence structure of the scale instructions to make it easier to understand.

\section{Study Design}

The study had a cross-sectional design.

\section{Setting and Sample}

The participants were frontline health care professionals who had graduated less than one year prior to the study. In total, 306 health care professionals (116 nurses, 169 clinical medicine staff members, 21 auxiliary service staff members) from one hospital in China responded to the Chinese version of the ATIHCTS. The numbers and percentages of the different health care professions who were invited to the study and responded to the scale are shown in Table 1.

\section{Data Collection}

According to the statistical sample size selection principle, the sample size is generally 5-10 times the number of scale items. ${ }^{17}$ Considering the factors such as nonstandard scale filling, $10 \%$ of the scales were expanded. The sample
Table I Respondent Characteristics

\begin{tabular}{|l|c|c|}
\hline Characteristics & N & $\%$ \\
\hline Gender $(n=306)$ & 108 & 35.3 \\
Male & 198 & 64.7 \\
Female & & \\
\hline Education background & & \\
(n=306) & 92 & 30.1 \\
College & 151 & 49.3 \\
Bachelor & 38 & 12.4 \\
Master & 25 & 8.2 \\
Doctor & & \\
\hline Major (n=306) & 169 & 55.2 \\
Clinical medicine & 116 & 37.9 \\
Nursing & 21 & 6.8 \\
Auxiliary services & & \\
\hline
\end{tabular}

Note: Auxiliary services members include radiologist, pharmacist and anesthesiologist.

size of this study was $n=14 \times 10 \times 1.1=154$. Exploratory factor analysis and confirmatory factor analysis (CFA) were needed in this study. Thus, the sample size was doubled to 308 .

A paper version of the ATIHCTS with an information letter about the study was distributed to the health care professionals in October 2020. To assist with survey dissemination, six investigators were recruited through one hospital. As part of their training, the investigators were familiarized with the purpose of the scale and its specific content. Completed scales were returned anonymously in self-addressed envelopes. No incentive was provided to the survey participants. A total of 312 respondents answered the survey, but six respondents who did not complete the ATIHCTS were removed from the sample. Therefore, the total sample size for the analysis was 306 .

\section{Data Analysis}

SPSS 25.0 and Amos 23.0 software were used for statistical analysis. In general data, counting data were described by frequency and constituent ratio (\%), measurement data were described by mean \pm standard deviation ( $\mathrm{x}$ $\pm \mathrm{s}$ ), and the independent samples $t$-test was used. Correlation analysis and the critical ratio method were used to analyze the reliability of the scale, Cronbach's $\alpha$ coefficient and split-half reliability were used to evaluate the reliability, and exploratory factor analysis and CFA were used to evaluate the construct validity of the scale. $\mathrm{P}<0.05$ was considered statistically significant. 


\section{Results}

Overall, 306 medical staff members were invited to the survey and completed the scales, and the average age was $(23.85 \pm 3.30)$ years.

Correlation analysis: Correlation analysis and the critical ratio method were used to evaluate the correlation level of the scale. The results of this study showed that the correlation coefficient between the items of the Chinese version of the ATIHCTS and the total scale was $0.369-0.798$, and the difference was statistically significant $(\mathrm{P}<0.01)$, indicating that each item had high homogeneity with the whole scale and the quality of each item was stable Thus, all items were kept. According to the total score before and after $21 \%$ as the grouping standard ${ }^{17}$, the respondents with scores in the top $27 \%$ (83) were named the high-score group (group 1), and the respondents with scores in the bottom $27 \%$ (83) were named the low-score group (group 2). ${ }^{18}$ The results of an independent samples $t$-test showed that there was a statistically significant difference $(\mathrm{P}<0.01)$ between the two groups. Moreover, the main mean score of group 1 $(\mathrm{M}=66.554, \mathrm{SD}=2.755)$ was significantly higher than that of group $2(\mathrm{M}=48.277, \mathrm{SD}=3.933)$. This meant that the Chinese ATIHCTS had good discrimination and all items could be retained.

Exploratory factor analysis: factor analysis was used to analyze the structural validity of the scale. The KMO test value of the 14 items on the Chinese version of the ATIHCTS was 0.927, and Bartlett's sphere test showed $\chi 2=3518.401, \mathrm{df}=91$, and $\mathrm{P}<0.001$, so it was suitable for factor analysis. The factor analysis revealed the presence of two components with eigenvalues exceeding 1, explaining $53.615 \%$ and $16.395 \%$ of the variance, respectively. Examination of the scree plot confirmed this, as it showed a clear break after the second component. Based on the results of this factor analysis, two main factors were extracted: quality of care (factor 1) and time constraints (factor 2). Combined, these two factors contained 14 items. The internal consistency measures for each of the two factors are displayed in Table 2. The factor loads of the two factors were all above 0.5 , and the load value of other common factors was low. Thus, it was concluded that the Chinese version of the ATIHCTS has good construct validity.

Confirmative factor analysis (CFA): Amos 23.0 software was used in this study to test the validity of the samples. In this study, the maximum likelihood method was used to verify the goodness of fit of the model. The
Table 2 Factor Loadings for the Items Contributing to the Two Principal Factors of ATIHCTS $(n=306)$

\begin{tabular}{|c|c|c|}
\hline Statement & Factor I & Factor 2 \\
\hline $\begin{array}{l}\text { QI Patients/clients receiving } \\
\text { interprofessional care are more likely than } \\
\text { others to be treated as whole persons }\end{array}$ & 0.623 & \\
\hline $\begin{array}{l}\text { Q3 The give and take among team } \\
\text { members helps them make better patient/ } \\
\text { client care decisions }\end{array}$ & 0.794 & \\
\hline $\begin{array}{l}\text { Q4 The interprofessional approach makes } \\
\text { the delivery of care more efficient }\end{array}$ & 0.850 & \\
\hline $\begin{array}{l}\text { Q5 Developing a patient/client care plan } \\
\text { with other team members avoids errors in } \\
\text { delivering care }\end{array}$ & 0.795 & \\
\hline $\begin{array}{l}\text { Q7 Working in an interprofessional } \\
\text { environment keeps most health professional } \\
\text { enthusiastic and interested in their jobs }\end{array}$ & 0.757 & \\
\hline $\begin{array}{l}\text { Q8 The interprofessional improves the } \\
\text { quality of care to patients/clients }\end{array}$ & 0.891 & \\
\hline $\begin{array}{l}\text { QI0 Health professionals working as teams } \\
\text { are more responsive than others to the } \\
\text { emotional and financial needs of patients/ } \\
\text { clients }\end{array}$ & 0.828 & \\
\hline $\begin{array}{l}\text { QII The interprofessional approach } \\
\text { permits health professionals to meet the } \\
\text { needs of family caregivers as well as } \\
\text { patients }\end{array}$ & 0.865 & \\
\hline $\begin{array}{l}\text { Q12 Having to report observations to a team } \\
\text { helps team members better understand the } \\
\text { work of other health professionals }\end{array}$ & 0.878 & \\
\hline $\begin{array}{l}\text { Q13 Hospital patients who receive } \\
\text { interprofessional team care are better } \\
\text { prepared for discharge than other patients }\end{array}$ & 0.893 & \\
\hline $\begin{array}{l}\text { Q14 Team meetings foster communication } \\
\text { among team members from different } \\
\text { professions or disciplines }\end{array}$ & 0.873 & \\
\hline $\begin{array}{l}\text { Q2 Developing an interprofessional patient/ } \\
\text { client care plan is excessively time-consuming }\end{array}$ & & 0.803 \\
\hline $\begin{array}{l}\text { Q6 Working in an interprofessional manner } \\
\text { unnecessarily complicates things most of the } \\
\text { time }\end{array}$ & & 0.913 \\
\hline $\begin{array}{l}\text { Q9 In most instances, the time required for } \\
\text { interprofessional consultations could be } \\
\text { better spent in other ways }\end{array}$ & & 0.885 \\
\hline
\end{tabular}

Notes: Factor 1: quality of care, factor 2: time constraints. Adapted from Curran VR, Sharpe D, Forristall J, et al. Attitudes of health sciences students towards interprofessional teamwork and education. Learn Health Soc Care. 2008;7(3): $146-156^{8}$ 
Table 3 Summary of Fit Indices

\begin{tabular}{|l|c|c|c|c|c|c|c|c|c|}
\hline $\mathbf{N}$ & $\mathbf{X}^{2}$ & $\mathbf{d f}$ & $\mathbf{X}^{2} / \mathbf{d f}$ & $\mathbf{C F I}$ & GFI & IFI & NFI & TLI & RMSEA \\
\hline 306 & 111.16 & 76 & 1.46 & 0.99 & 0.97 & 0.99 & 0.97 & 0.99 & 0.04 \\
\hline
\end{tabular}

Abbreviations: RMSEA, root mean square of approximation error; NFI, normalized fit index; TLI, the Tucker-Lewis index; IFI, incremental fit; CFI, comparative fit index.

chi-square/degrees of freedom ratio $(\mathrm{X} 2 / \mathrm{df})$, root mean square error of approximation (RMSEA), normed fit index (NFI), Tucker-Lewis index (TLI), incremental fit index (IFI), and comparative fit index (CFI) were used to verify the goodness of fit of the model. It can be seen from Table 3 that most of the fitting values meet the judgment standard, which indicates that the Chinese version of the ATIHCTS CFA model fits well. Through the model fitting, the results showed that the loads of the two factors of nursing quality and time control in the text version of the ATIHCTS were all above 0.5 , with the factor load for quality of care ranging from 0.56 to 0.90 , that for Item Q13 up to 0.90 , and that for time constraints ranging from 0.65 to 0.93 . The load for Item Q6 was the highest, as shown in Figure 1. Therefore, it was shown that the Chinese version of the ATIHCTS has good validity.

Reliability analysis: See Table 4 . To further understand the reliability of the scale, this study used the internal consistency coefficient and split-half reliability to measure the reliability of the scale. (1) Internal consistency coefficient. The overall Cronbach's $\alpha$ coefficient of the Chinese version of the ATIHCTS was 0.861 , and the Cronbach's $\alpha$ coefficient of each factor was $0.838-0.949$. It can be seen that the reliability and total reliability of each factor of the Chinese version of the ATIHCTS were above 0.8, showing that this scale has good reliability. (2) Split-half reliability. The overall Guttman split-half reliability of the Chinese version of the ATIHCTS was 0.644, and the Guttman coefficient of each factor was $0.779-0.904$, showing that the internal consistency of the scale was good.

Tables 5 and 6 show the results of supplementary tests. In relation to the whole scale, female staff members showed more positive attitudes than male staff members $(\mathrm{p}=0.022)$, and their mean score $(\mathrm{M}=57.9)$ was slightly higher than that of male staff members $(M=55.9)$. However, no large difference was seen on the Quality of Care subscale or the Time Constraints subscale. Experience also had no association with either scale. A single-factor ANOVA was used to compare different majors, but no difference was seen among the groups on each scale, and $\mathrm{P}$ values were greater than 0.05 .

\section{Discussion}

The findings from the study confirmed that the Chinese version of the ATIHCTS is a reliable and valid instrument for assessing Chinese health care professionals' attitudes toward the concept of interprofessional health care teamwork. No significant difference was found between the attitudes of medicine and nursing professionals toward interprofessional health care teamwork. Gender appeared to have a significant correlation with attitudes toward interprofessional health care teamwork. Female health care professionals reported more positive attitudes toward interprofessional teamwork. The results of a study by Sollami et al showed that women achieved higher scores than men after IPE training. ${ }^{19}$ The finding suggests that the women students might have benefited more from IPE training than did the men. Attention may be needed to find ways to improve the men students' outcomes. In the study of Darlow et al, they explored the impact of a pre-registration IPE immersion program on long-term outcomes in a large cohort of students and graduates from the disciplines of dentistry, dietetics, medicine, nursing, occupational therapy, oral health, pharmacy, and physiotherapy recruited before their final year of study. ${ }^{13}$ The ATIHCTS was used as the measurement tool, as it had been found to have high internal consistency when completed by health professional students. Similar to some previous studies, ${ }^{8,12,15}$ we found that health care professionals valued teamwork and collaboration and that their positive attitudes played an important role in enhancing quality of patient care.

Another purpose of the study was to investigate whether the two-factor model from the ATIHCTS could be applied to the Chinese translation of the scale in a Chinese setting. According to model fitting, the factor loads for the Quality of Care and Time Constraints subscales of the Chinese version of the ATIHCTS were mostly above 0.5 . The goodness of fit of the model was a prominent factor regarding the validity of the instrument. In the study of Hayashi et al, the ATIHCTS was used to evaluate changes in attitudes toward interprofessional health care teams in first- and third-year undergraduate students. ${ }^{12}$ The result showed that the KMO index was 0.864 , indicating sampling adequacy, and the Bartlett sphericity chi-square index was $1473.76(\mathrm{p}<0.001)$. 


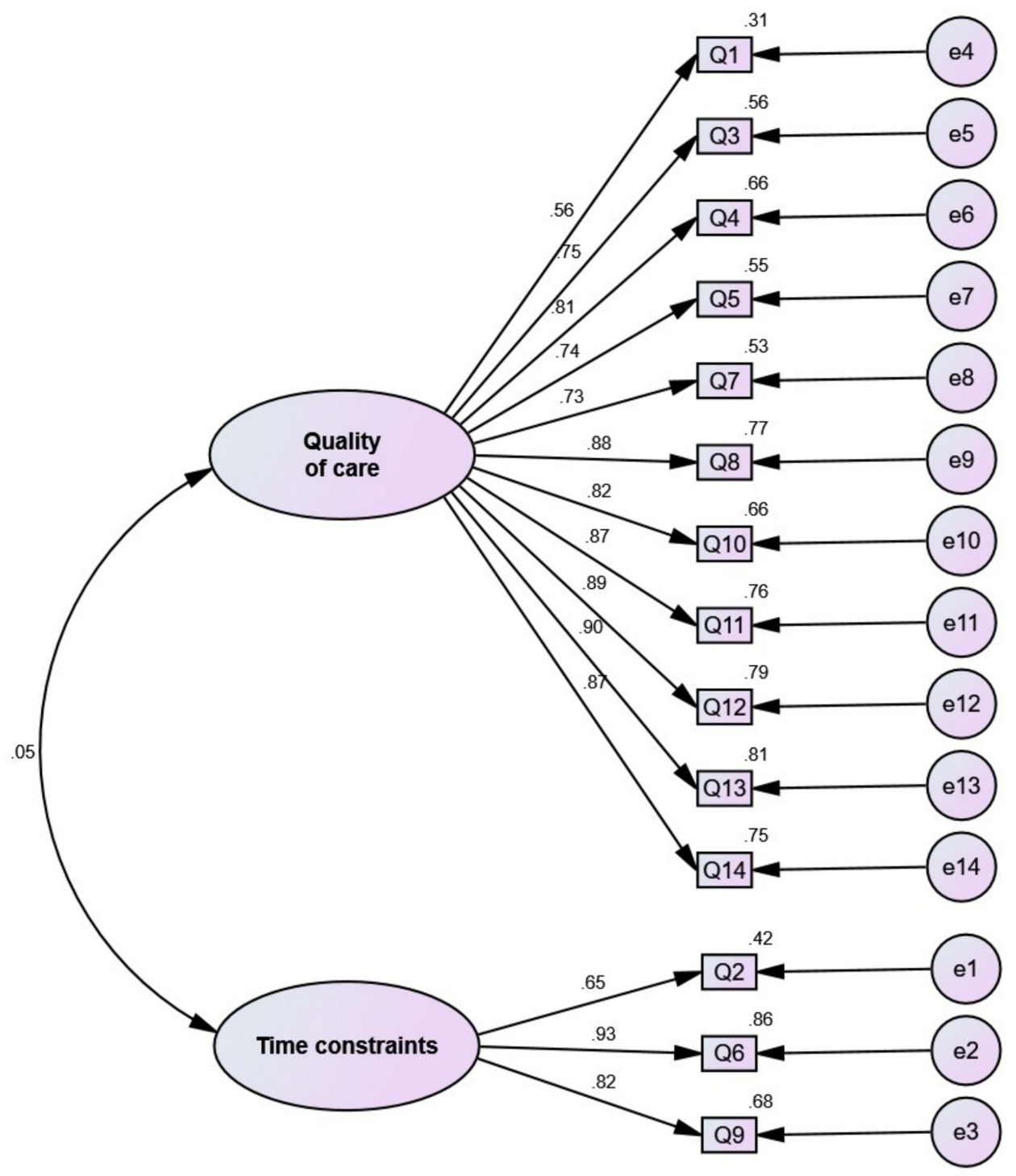

Figure I Confirmatory factor analysis model diagram of the ATIHCT scale $(n=306)$. Rectangle represents measurement index, three items (Q2, Q6, and Q9) load onto the Time Constraints subscale, and the remaining II items (QI, Q3, Q4, Q5, Q7, Q8, Q10-Q14) load onto the Quality of Care subscale, and circle el-el4 represents residual variables. The Chinese version of the ATIHCT scale model was comprised of 14 items. Through the model fitting, the results show that the load of the two factors of quality of care and time constraints were all above 0.5 , with the factor load for the quality of care ranging from 0.56 to 0.90 , the factor load for Item $\mathrm{Q} / 3$ up to 0.90 , and the factor load for the time limit ranging from 0.65 to 0.93 , with the load for Item Q6 was the highest.

Cronbach's $\alpha$ of the 14 items was 0.773 , revealing a high rate of internal consistency. Three subscales were obtained from the analysis of the ATIHCTS: "Quality of Care Delivery," "Patient-centered Care," and "Team Efficiency" with Cronbach's $\alpha$ measures of $0.718,0.676$, and 0.427 ,

Table 4 Reliability of the ATIHCTS

\begin{tabular}{|l|c|c|}
\hline Item & Cronbach's $\alpha$ & Guttman Split-Half \\
\hline Total factors & 0.861 & 0.668 \\
Quality of care & 0.949 & 0.904 \\
Time constraints & 0.838 & 0.779 \\
\hline
\end{tabular}

respectively. In the study of Curran et al, two main factors were extracted: "quality of care" and "time constraints." Hayashi et al discussed why items making up a single subscale in the other studies were divided into two subscales in the present analysis of the ATIHCTS. The total number of items used for the survey likely led to the difference, since in the 14-item instrument developed by Curran et al, items containing the word "physician" have been removed from the original 21 -item instrument. ${ }^{12}$ Alternatively, it might have been because the participants between pre- and postqualification health care professionals in the different studies differed. It is likely that incorporation of the two separate 
Table 5 Mean Scores for Total Scale

\begin{tabular}{|l|c|c|c|}
\hline \multirow{2}{*}{} & \multicolumn{2}{|c|}{ Total Scale } \\
\cline { 2 - 4 } & M (SD) & F or t & P \\
\hline $\begin{array}{l}\text { Gender } \\
\text { Male } \\
\text { Female }\end{array}$ & $55.9(7.9)$ & $\mathrm{t}=-2.30$ & 0.02 \\
\hline $\begin{array}{l}\text { Prior experience } \\
\text { Yes }\end{array}$ & $57.9(7.0)$ & & \\
No & $57.0(7.6)$ & $\mathrm{t}=-0.22$ & 0.83 \\
\hline $\begin{array}{l}\text { Major } \\
\text { Clinical medicine }\end{array}$ & $57.2(7.4)$ & & \\
Nursing & $57.0(7.7)$ & $\mathrm{F}=0.22$ & 0.80 \\
Auxiliary services & $56.6(6.8)$ & & \\
\hline
\end{tabular}

Notes: Independent samples $t$-test was used to compare the Gender and prior experience difference. $p<0.05$ that means has significant difference. A one-way between group ANOVA was conducted to explore the effect of different majors, $P$ values presents the significance.

subscales, "Quality of Care Delivery" and "Patient-centered Care," into one single subscale is due to practice experience in a health care center or hospital. ${ }^{12}$

IPE has increasingly become the impetus behind interprofessional collaboration in patient care. IPE enables the sharing of skills and knowledge among health care professions and promotes better understanding, shared values, and mutual respect within the health care team. ${ }^{20,21}$ Early exposure of health care professionals to IPE is required for a positive attitude toward interprofessional collaboration. ${ }^{22}$ Hospital administrators should facilitate conducive work environments that promote interprofessional collaboration and promote programs that could address the challenges of teamwork. $^{23}$ The ATIHCTS offers a simple IPE assessment tool that reflects attitudes toward interprofessional health care teams.

This study is the first to use the Chinese version of the ATIHCTS, and our aim was to test if the developed Chinese ATIHCTS is usable for assessing attitudes toward interprofessional health care teams among Chinese health care professionals. The Chinese ATIHCTS can facilitate discussion, leading to better development of IPE and interprofessional collaborative practice.

\section{Limitations}

The study has several limitations. The data-collection sample and location were limited to the health care professionals in one tertiary hospital in Shanghai. All participants were in their first year of work. Research could be done among health care professionals in different years of work. The study sample came from only one hospital in China, which may not be representative of all Chinese health care professionals. Further studies examining varying levels of participants from different hospitals are needed to confirm the stability of the structure of the Chinese version of the ATIHCTS. The sample size of auxiliary services staff members was not large enough to be representative. The sample sizes from the disciplines of anesthesia, medical imaging, and pharmacy were much smaller than those of nursing and medicine. Future research would benefit from evaluating health care professionals from different medical majors to explore the validity and reliability among different populations. When using the Chinese ATIHCTS to evaluate Chinese health care professionals, we did not use other

Table 6 Mean Scores for Each Subscale

\begin{tabular}{|c|c|c|c|c|c|c|}
\hline & \multicolumn{3}{|c|}{ Quality of Care } & \multicolumn{3}{|c|}{ Time Constraints } \\
\hline & $M(S D)$ & $\mathbf{F}$ or $\mathbf{t}$ & $\mathbf{p}$ & $M(S D)$ & $F$ or $\mathbf{t}$ & $\mathbf{P}$ \\
\hline \multicolumn{7}{|l|}{ Gender } \\
\hline Male & $47.1(7.2)$ & $\mathrm{t}=-1.90$ & 0.06 & $8.78(3.5)$ & $t=-1.36$ & 0.17 \\
\hline Female & $48.6(5.9)$ & & & $9.34(3.5)$ & & \\
\hline \multicolumn{7}{|l|}{ Prior experience } \\
\hline Yes & 47.9 (6.9) & $t=-0.23$ & 0.82 & $9.13(3.3)$ & $t=-0.03$ & 0.97 \\
\hline No & $48.1(6.3)$ & & & 9.14 (3.5) & & \\
\hline \multicolumn{7}{|l|}{ Major } \\
\hline Clinical medicine & $47.7(6.7)$ & $F=1.49$ & 0.22 & $9.3(3.5)$ & $F=1.83$ & 0.16 \\
\hline Nursing & $48.8(5.8)$ & & & $8.8(3.5)$ & & \\
\hline Auxiliary services & $46.7(6.8)$ & & & $10.2(2.8)$ & & \\
\hline
\end{tabular}

Notes: Independent samples $t$-test was used to compare the Gender and prior experience difference. $p<0.05$ that means has significant difference. A one-way between group ANOVA was conducted to explore the effect of different majors, $P$ values presents the significance. 
relevant evaluation tools for comparison. This provides a topic for further research.

\section{Conclusion}

The reliability and validity of the Chinese version of the ATIHCTS with this study's sample were considered good. The two-factor model indicated that the construct validity of the ATIHCTS was demonstrated in the Chinese cultural context. The subscales were concise and easy to understand.

\section{Ethics}

The Research Ethics Committee at Shanghai East Hospital approved the study (No. 2020162). By completing and returning the scale, the health care professionals consented to participate in the study.

\section{Acknowledgment}

Dan Li and Ai-li Wang should be considered to be first authors.

\section{Author Contributions}

All authors made substantial contributions to conception and design, acquisition of data, or analysis and interpretation of data; took part in drafting the article or revising it critically for important intellectual content; agreed to submit to the current journal; gave final approval of the version to be published; and agreed to be accountable for all aspects of the work.

\section{Funding}

The research reported in this publication was supported by the project of academic leader training in healthcare system of Pudong New District, Shanghai, China (No. PWRd2016-13), the project of scientific research program of shanghai municipal health and family planning committee, Shanghai, China (No. 201840055) and the project of scientific research program of Health Commission, Jiangxi, China (No. 202120111).

\section{Disclosure}

The authors report no conflicts of interest in this work.

\section{References}

1. Hall-Lord ML, Skoogh A, Ballangrud R, et al. The Swedish Version of the TeamSTEPPS ${ }^{\circledR}$ Teamwork Perceptions Questionnaire (T-TPQ): a Validation Study. $J$ Multidiscip Healthc. 2020;13:829-837. doi:10.2147/JMDH.S261768

2. Schmutz JB, Meier LL, Manser T. How effective is teamwork really? The relationship between teamwork and performance in healthcare teams: a systematic review and meta-analysis. BMJ Open. 2019;9(9): e028280. doi:10.1136/bmjopen-2018-028280
3. Shrader S, Farland MZ, Danielson J, et al. A systematic review of assessment tools measuring interprofessional education outcomes relevant to pharmacy education. Am J Pharm Educ. 2017;81(6):119. doi:10.5688/ajpe816119

4. Salvati LA, Weber ZA, Trinh M, et al. An assessment of interprofessional education in schools/colleges of pharmacy in the United States. Curr Pharm Teach Learn. 2020;12(6):626-632. doi:10.1016/j. cpt1.2020.01.030

5. Lestari E, Stalmeijer RE, Widyandana D, et al. Understanding attitude of health care professional teachers toward interprofessional health care collaboration and education in a Southeast Asian country. J Multidiscip Healthc. 2018;11:557-571. doi:10.2147/ JMDH.S178566

6. Reeves S, Perrier L, Goldman J, et al. Interprofessional education: effects on professional practice and healthcare outcomes. Cochrane Database Syst Rev. 2013;3. doi:10.1002/14651858.CD002213.pub3

7. Ulrich G, Homberg A, Karstens S, et al. Attitudes towards interprofessional collaboration in young healthcare professionals. J Interprof Care. 2019;33(6):768-773. doi:10.1080/13561820.2019.1597839

8. Curran VR, Sharpe D, Forristall J, et al. Attitudes of health sciences students towards interprofessional teamwork and education. Learn Health Soc Care. 2008;7(3):146-156. doi:10.1111/j.14736861.2008.00184.x

9. Heinemann GD, Schmitt MH, Farrell MP. Attitudes toward health care teams. In: Heinemann GD, Zeiss AM, editors. Team Performance in Health Care: Assessment and Development. New York: Kluwer Academic/Plenum Publishers; 2002:155-159.

10. Heinemann GD, Schmitt MH, Farrell MP, Brallier SA. Development of an attitudes toward health care teams scale. Eval Health Prof. 1999;22(1):123-142. doi:10.1177/01632789922034202

11. Kim K, Ko J. Attitudes Toward Interprofessional Health Care Teams Scale: a confirmatory factor analysis. J Interprof Care. 2014;28 (2):149-154. doi:10.3109/13561820.2013.857645

12. Hayashi T, Shinozaki H, Makino T, et al. Changes in attitudes toward interprofessional health care teams and education in the first- and third-year undergraduate students. $J$ Interprof Care. 2012;26 (2):100-107. doi:10.3109/13561820.2011.644355

13. Darlow B, Brown M, Gallagher P, et al. Longitudinal impact of interprofessional education on attitudes, skills and career trajectories: a protocol for a quasi-experimental study in New Zealand. BMJ Open. 2018;8(1):e018510. doi:10.1136/bmjopen-2017-018510

14. Kelly PL, Heyman JC, Tice-Brown D, et al. Interprofessional practice: social work students' perspectives on collaboration. Soc Work Health Care. 2020;59(2):108-121. doi:10.1080/00981389.2020.1719565

15. Ong SY, Tan NC, Knab MS, et al. Attitudes of clinician educators towards interprofessional education and collaboration: insights from two interprofessional scales. J Interprof Care. 2017;31(5):656-660. doi:10.1080/13561820.2017.1320275

16. Li Z, Sun Y, Zhang Y. Adaptation and reliability of the Readiness for Inter Professional Learning Scale (RIPLS) in the Chinese health care students setting. BMC Med Educ. 2018;18(1). doi:10.1186/s12909018-1423-8

17. Wu ML. Practice of Questionnaire Statistical Analysis. Chongqing: Chongqing University Press; 2010:41-207.

18. Wu ML. SPSS Statistical Application Practice: Questionnaire Analysis and Applied Statistics. Beijing: Science Press; 2003.

19. Sollami A, Caricati L, Mancini T. Attitudes towards interprofessional education among medical and nursing students: the role of professional identification and intergroup contact. Curr Psychol. 2018;37 (4):905-912. doi:10.1007/s12144-017-9575-y

20. Karim R, Ross C. Interprofessional education (IPE) and chiropractic. J Can Chiropr Assoc. 2008;52(2):76-78.

21. Wang Z, Feng F, Gao SH, et al. A systematic meta-analysis of the effect of interprofessional education on health professions students' attitudes. J Dent Educ. 2019;83(12):1361-1369. doi:10.21815/ JDE.019.147 
22. Zechariah S, Ansa BE, Johnson SW, et al. interprofessional education and collaboration in healthcare: an exploratory study of the perspectives of medical students in the United States. Healthcare (Basel, Switzerland). 2019;7(4). doi:10.3390/ healthcare7040117.
23. Ansa BE, Zechariah S, Gates AM, et al. Attitudes and behavior towards interprofessional collaboration among healthcare professionals in a large academic medical center. Healthcare (Basel, Switzerland). 2020;8(3). doi:10.3390/healthcare8030323.

\section{Publish your work in this journal}

The Journal of Multidisciplinary Healthcare is an international, peerreviewed open-access journal that aims to represent and publish research in healthcare areas delivered by practitioners of different disciplines. This includes studies and reviews conducted by multidisciplinary teams as well as research which evaluates the results or conduct of such teams or healthcare processes in general. The journal covers a very wide range of areas and welcomes submissions from practitioners at all levels, from all over the world. The manuscript management system is completely online and includes a very quick and fair peer-review system. Visit http://www.dovepress.com/testimonials. php to read real quotes from published authors. 